\title{
Experiences of Mothers of Children Born with Celebral Palsy in Oshana Region: Namibia
}

\author{
Sankombo Marian ${ }^{1}$, Emmanuel Magesa ${ }^{2} \&$ Nakakuwa Fillipine ${ }^{3}$ \\ ${ }^{1}$ School of Nursing, University of Namibia, Rundu, Namibia \\ ${ }^{2}$ Welwitchia University, Windhoek, Namibia \\ ${ }^{3}$ School of public health, University of Namibia, Rundu, Namibia \\ Correspondence: Emmanuel Magesa, Welwitchia, Windhoek, Namibia. Tel: 264-8136-8905. E-mail: \\ emagesa2002@yahoo.com
}

Received: September 29, 2019 Accepted: December 12, 2019 Online Published: December 15, 2019

doi:10.5539/gjhs.v12n1p72 URL: https://doi.org/10.5539/gjhs.v12n1p72

\begin{abstract}
Cerebral Palsy is a neurological disorder caused by a non-progressive brain injury or malformation that occurs while the child's brain is under development. This type of birth defects, pose a public health concern to the society, immediate family members and individual parents. The parents' expectations to have a normal child becomes a nightmare when the child they were expecting is born with cerebral palsy. Therefore, revealing the experiences of mothers of children born with Cerebral Palsy is important in the process of finding ways to support these mothers and their children. The study explores and describes the experience of mothers of children with cerebral palsy. A qualitative approach following phenomenological, explorative and descriptive design was used to explore and reveal the experiences of mothers of children with Cerebral Palsy. The population for this particular study consisted of mothers of children with cerebral palsy in Oshana region and a sample was drawn from this population using purposive sampling method. Data were collected through indepth interview with 12 (twelve) mothers. The transcribed interviews and narratives from the research notes were organised into codes, main themes and sub-themes. Mothers were shocked, worried and were in the state of disbelief when they learnt about the condition of their children. They felt guilty about the child's disability and blamed themselves as the reason for the disability of their children. They were traumatized by a family member or spouse who failed to accept the child with cerebral palsy. In order to alleviate the psychological stress, trauma, pain and disappointments, it is of utmost importance to develop an educational support program in the form of a stress coping framework to support these mothers to cope with the high stress levels. centers where they can overcome their psychological problem. There is a need for a coordinating body or counselling centers where parents of children with cerebral palsy should be referred after the final diagnosis is made to give appropriate direction and couselling to these parents, thus reducing stress levels.
\end{abstract}

Keywords: mother, experience, children, cerebral palsy

\section{Introduction and Background}

Cerebral Palsy (CP) is a long life, congenital disorder that is evident either at birth or during the early life of a person. It is defined as a neurological disorder caused by a non-progressive brain disorder or an injury to the brain sustained during pregnancy, labor, and delivery or shortly after birth (Karande, Patil, \& Kulkarni, 2008). It is one among the eminent problems in the society that affects the livelihood of the individual, communities and the health sector. The condition also creates uncertainty among families as they strive to identify ways and means to assist one another in the upbringing of such children. The serious consequences of CP may induce the process of parental mourning and victims are liable to suffer psychological stress which may eventually lead to life styles health conditions (Bouman, 1999). Furthermore, CP is a complex societal problem characterized, by social, psychological and economic implications requiring a collective multisectoral approach.

Accurate data on the incidence or prevalence of $\mathrm{CP}$ in most of developing countries is not available. In developed countries CP occurs in about 2 to 2.5 per 1,000 live births ((Karande et al., 2008). The incidence is significantly low, especially in countries where there are improved medical services that minimizes risk factors for CP such as instrument deliveries, birth asphyxia, intra-partum hemorrhage, neonatal septicemia and neonatal convulsions. 
According to the population based studies around the world, CP prevalence stands at 1.5 to 4 per 1000 live births, incidence in Europe is 2 per 1000 live births and higher among males than females (Braeneuner \& Media, D2017).

In Namibia, the current health information system is not capturing cerebral palsy as a data element on its own, but it is included under disability data element, this makes it difficult for the system to generate reports of both incidence and prevalence of $\mathrm{CP}$ in the country. However, registers are kept at various occupational health departments or physiotherapy departments where they record all children with CP. According to the occupational health worker at Intermediate Hospital Oshakati a significant number of parents of children with CP bring their children for therapy on a monthly basis and they mostly concentrate on children in the age group of 0-5 years. Children above 5 years are discharged from the departments as it is anticipated that at this age parents of children with $\mathrm{CP}$ could have mastered the skills aiming at improving the motor function of children with CP. Meanwhile, children above 5 years are referred to the community based rehabilitation center where they are being followed up for continuity of care.

According to the 2011 population and housing survey, the prevalence of disability which include cerebral palsy in Namibia stood at 6.7 which translates to 85000 people (National Policy Framework, 2010-2020. Namibia as a developing country together with its developmental partners has done more in terms of caring for people with disability including children with cerebral palsy. National policies have been drafted and adopted, these policies are mainly concerned with removing the barrier that may stand in the way of people, including children with disabilities' full integration into the society so that they have the opportunity for a quality life equal to any other member of the society ( MoLRR, 1997). Thus, the Government should ensure that disability aspects are included in all relevant policy- making and national planning activities.

Moreover, guidelines and Community based training manuals are in place to guide parents and rehabilitation service providers as they are the providers of care to the disabled members of the society. Social nets that give a positive socioeconomic support to families and disabled members are provided. However, psychological support for parents of disabled children is lacking. Given the hypothetical levels of stress envisaged among parents of congenitally abnormal children, this problem of psychological neglect of these people makes them vulnerable to stress outcome as they do not have any coping mechanism in place.

Given the hypothetical levels of stress envisaged among mothers of cerebral palsy children, this problem makes mothers vulnerable to negative outcomes as they do not have any strong and reliable support. It is against this background that a qualitative study on experience of mothers of children born with cerebral palsy in Oshana region was explored as a prerequisite to the initiation of support for mothers with cerebral palsy children in Oshana region, Namibia.

\section{Purpose of the Study}

The purpose of this study was to reveal the experience of mothers of children born with cerebral palsy in Oshana region, Namibia.

\section{Research Design and Methods}

\subsection{Design}

A qualitative approach following phenomenological, explorative and contextual design was employed to reveal the lived experiences of mothers of children with cerebral palsy.

\subsection{Study Population}

The population for this study were mothers of children with CP at Intermediate Hospital Oshakati (IHO) in Oshana region, Namibia.

\subsection{Inclusion and Exclusion Criteria}

The criteria used to select study participants were mothers of children under 14 years born with cerebral palsy who were admitted in the hospital or those who brought their children for follow up.

\subsection{Sampling and Sample Size}

In qualitative studies the size of a sample is guided by the saturation point. In this study saturation point reached with (12) mothers (participants). The study used non probability "purposive" sampling method, in which cohort registers were used to identify some of the study participants.

\subsection{Data Collection Procedures}

In-depth interviews were conducted with twelve study participants. During the interview sessions, the researcher 
with the assistance of field worker wrote verbatim notes (real words from mothers) to capture key issues and non-verbal language of study participants. Furthermore, the interviews were recorded using a tape recorder to assist the researcher not to miss any valuable information for the study.

\subsection{Data Analysis}

The transcribed interviews were coded into three themes and five sub-themes. A content data analysis method was used in order to analyze the meaning of themes.

\section{Ethical Considerations}

The researcher sought permission from the University of Namibia (UNAM), School of Public Health, Ministry of Health and Social Services (MoHSS) and from respective study sites. Furthermore, the researcher made sure that all aspects of the study were handled in a way which was respectful of the human rights.

\section{Results}

\subsection{Socio Demographic Characteristics of the Participants}

A total of 12 mothers (participants) were interviewed with a mean age of 33 years. Over $60 \%$ of mothers were unemployed and only $8 \%$ had formal employment, the remaining mothers owned small businesses which were not significant enough to respond to their children's demands.

Table 1. Characteristics of mothers

\begin{tabular}{ll}
\hline Age group & n \\
\hline $17-21$ & 3 \\
$22-35$ & 4 \\
$36+$ & 5 \\
\hline Employment status & \\
\hline Formal employment & 1 \\
Self- employment - & 3 \\
Unemployed & 8 \\
\hline Level of education & \\
\hline Grade 1-7 - & 2 \\
Grade 8-10 & 9 \\
Grade 11-12 & 1 \\
Tertiary & 0 \\
\hline
\end{tabular}

\subsection{Themes and Sub-Themes}

Table 2. Themes and sub-themes

\begin{tabular}{ll}
\hline Themes & Sub-themes \\
\hline 5.2. The emotional experiences of mothers of & 5.2 .1 Mother 's immediate reaction \\
children with cerebral palsy & 5.2 .2 Experiences with family relationships \\
& 5.2 .3 Altering one's family daily life- treading a new path \\
\hline 5.3 Social Support & None \\
\hline 5.4. Community acceptance & None \\
\hline
\end{tabular}

Four themes of description reflecting key variations of meaning emerged from the analysis. The commonalities and variations in mothers' descriptions are illustrated with excerpts from the transcripts.

\subsection{Theme 1: The Emotional Experiences of Mothers of Children with Congenital Abnormalities This Theme Describes the Experience of Mothers towards the Birth of a Child with Cerebral Palsy}

This theme and its three sub-themes clearly indicate the emotional and psychological challenges endured by the mothers when raising a child born with cerebral palsy. This includes the mother's immediate reaction after they learned about the child's condition, their experiences with family members when they revealed the news about the existence of the condition, their expectations and practices after learning about their child's condition as well as push and shifts that mothers have to undergo to reposition themselves to better care and understand the problem. 


\subsubsection{Sub-Theme1 Mother's Immediate Reaction}

The knowledge that their child had CP came after the child was born, all mothers in this study learnt about the condition of the child after was born and mainly when these children could not attain the developmental milestone according to their age. For all the mothers, this knowledge brought trepidation and apprehension because they possessed little knowledge about the disorders. The majority (9) of the mothers were uneducated with either grade 10 or lower as the highest passed grade. Some of them still feel bitter in their hearts, showed signs of very low self esteem and physically cry when they reflect on and see their children with congenital disorders. Variations in reaction and its impact were observed in the excerpts that follow:

A 36 year old mother has this to say:

"I was shocked, I became sick and I developed high blood pressure. I started thinking a lot of things asking myself what I did wrong to my God, what did I do to deserve this?"

"I was afraid and I kept asking myself, will there be any help for the baby or it was the end of everything, it affected me so much that I do not feel good about it."

\subsubsection{Sub-Theme 2: Experiences with Family Relationships}

Some of the participants highlighted the importance of support from their partners and family members. While some participants highlighted positive reaction and support from family systems, others expressed dissatisfaction, they were psychological traumatized by the fact that family members were not at easy with the child.

"My family and husband's family are fine with the child, like now the child stays with my mother in-law and I know she treats the child well, mmm!!!! The problem is that she is too old. I once decided to take the child to Windhoek, but I thought again that the child was still small to be sent to Windhoek."

A 33 year old mother of a cerebral palsy has a good relationship with her husband, but the relatives of the husband have traumatized them so much as expressed below:

"My husband is depressed because his family did not accept the child up to now. They used to tell him bad words like he is stupid, he is having a disabled child. One time this year (2013) in May he was on leave at home and one of his uncles (grandfather) asked him to take him to the cattle post and he responded that he is busy because he is taking child to the hospital for measurement of the wheelchair. The uncle said for what purpose if the person is disabled, what it is going to help, for what reason, so he is always depressed."

"Yes (she lowers her voice), I told him at a later stage, he just asked where did he get the abnormality. I said I don't know also (still speaking in a low voice)."

Asked how she felt about the spouse's response, this mother responded with difficulty:

"I felt very bad since I did not know how to explain it to him (Her voice is breaking as she wants to cry), but later he accepted the child."

"........ No support from other family members" and continues crying

\subsubsection{Sub-Theme 4: Altering One's Family Daily Life- Treading a New Path}

This sub-theme exposes the push and shifts that the family undergoes as they reposition themselves to better the care and understanding the condition of their child. Suddenly the mother finds herself in a position where she has to adjust the family daily life and enter a new path, sometimes in a different direction and at times within the same direction The theme also exposes vulnerability to everyday activities that mothers undergoes and in other moments, re-organizing themselves and showing a disposition based on what is to come. These push and pulls mostly results in high stress levels trigerring emotions of anger and fear of what the future holds for them. This is illustrated in the following excerpts:

Yes, it affects me very much. Like now I don't go to my business in the morning because of the child, I go in the afternoon when the school is out for the sisters to stay with him when I am gone. I used to take him but I failed, he is now to heavy to be carried to the open-market. I dropped the business because there is no one to look after the child."

"Every time you need to wash the child and change nappies; you have to buy nappies every time. You must feed the child every time she needs food, every second she needs food."

"You know, you cannot leave the child behind; anyway you can leave her with other people or at kindergarten but it is not good"

"The challenges are more, let us start with feeding; the child cannot feed himself, somebody has to feed him. Like 
now, I am at work, the child is with my mother, she is the only one to feed this child, bath and so on. I am having sisters but most of the time they are at school. The child cannot do anything or help himself, he is just there not walking. I have been buying expensive disposable nappies from birth up to now, he is a big boy so I always buy the largest size of those nappies which is XX large. Now I really don't know where I will get disposable nappies of his size."

\subsection{Theme 2: Social Support}

This represents the mothers' experiences with the social support services outside the family. It focused on mothers' experiences with existing social networks which included among others meeting other parents who had a child with a similar problem. The study revealed the role played by Faith Based Organization (FBO) including pastors, assistance from a formal institution such the hospital. This is confirmed by the following:

"The words from the pastor and my husband assisted me to accept the situation because after that, I did not even consider what my mother in -law was accusing me of doing something to my child. After birth it was hard to accept, but the hospital Pastor came and advised me to pray every day, because at least I gave birth to a live child, I should thank God for that and accept what God has given me, so I accepted. Then by that time I was relieved from worries. The other thing when my husband told me about one of his family members with the same condition and after seeing this cousin of my husband, I became much better and I accepted my child."

"What gives me, courage is that whenever I bring my child to the hospital, I will see that we are many parents who are having disabled children and when we are here, we normally share ideas on how to care for our children."

"Whenever you bring the child to the hospital, you feel relieved to see that your child is even better than other children, Other conditions are worse, you will think that the child is dead"

\subsection{Theme 3: Formal Services}

This theme represents the mothers' experiences with health care services primarily. It focused on mothers' experiences with professionals. Most of the interviewed mothers were furious about health care workers' failure to disclose the condition of their children as well as failure to give as much information about the condition. They felt that health workers have a role to play to assisting them. The following excerpts illustrate the mothers' feelings about health workers.

"They were supposed to inform me immediately after the birth of my child" (Starts crying), I could not have sent my child to South Africa, I could have stayed with my child"

"I think they need to improve!! You know last month I brought my child they took X-ray and they told me to come to this center (Occupational therapy) where I was told to play with the child, I was given a follow-up date, but still when I came back I am told to play with the child, I can play with the child even at home. If they can tell me the problem of the child and try to change, then maybe things could be better."

"The problem is that they don't know or they don't want to tell you about how the child will develop in the future...will he be able to go to school? Will he be able to work or to get married?"

"You don't know which way to turn...how to find the strength to accept this illness."

\section{Discussion}

\subsection{Mother's Immediate Reaction}

The birth of the baby is a major event in the life cycle of the family and a source of great expectations, so giving birth to a baby who manifests with a different appearance or who presents with life threatening conditions triggers a series of reactions (Carsle, Mason, Watkins, \& Whitehead, 2005). This notion coincides with the results of this study which revealed that mothers 's dreams of having a normal child were shattered, they even went to an extent of questioning the divine creation (what I did wrong to my God, what did I do to deserve this?). Some mothers were shocked, scared, depressed and they cried. The emotional experience of sadness, inner pain or bitterness in this current study is similar to the previous study done in the United States where emotional strain was expressed by mothers as having fear, frustration and guilt (Scharer, Colon, Moneyham, Hussey et al., 2009).

\subsection{Experiences with Family Relationships}

Families are the pillars of strength to lean on during difficult moments. In most cases, problems bring families closer to each other and most of the people feels safe when they are with their families. In this study some mothers reported good supportive family relations. Family members have been supportive since the birth of the child with cerebral palsy, the support included both emotional, psychological, material and financial support. asserts that families Rosenweig \& Huffutter (2003)with children born with congenital abnormalities tend to function more 
successfully with strong support system. Moreover, Contact a Family (2013) asserts that relationships matter and when they work well, they are a vital source of support and protection against life's stresses and strains.

However, the majority of the mothers interviewed in this study had nasty relationships with their families. Some spouses of the mothers of children with cerebral palsy, rejected them and never supported them financially or materially. Some of the spouses, family members and the extended families never even came to visit the child at all and blamed mothers as the cause of the disorder, hence they increase the level of stress to the mothers. Some of the spouses repudiated mothers because of the presence of a congenitally disorder child in the family. Mothers were accused of witchcraft or adultery as reasons for giving birth to congenital disorder children. Some family members started calling mothers of children with cerebral palsy names (One no maulema eni in the vernacular, meaning you people with your disabilities). In their endeavour not to accept the disabled child, the family can end even calling names of the mother. This name calling constantly reminds the mother of her disabled child, even when she moves around the community in search of free space. Name calling may result in bitter feeling, social isolation and depression. In the family support and direct character assignation by the people who are supposed to be pillars of strength of the mother, the mother is vulnerable emotionally and mentally. This is in line with Sajjad (2010), who asserted that, anger, sense of loneliness and depression faced by mothers of children with intellectual disability has a negative impact on their family life. Despite increased levels of stress experienced, mothers interviewed in this study overlooked their own agony and suffering and concentrated more on what might work well for their disabled children.

\subsection{Altering One's Family Daily Life- Treading a New Path}

Some of the mothers in this study experienced financial challenges attached to caring a child with cerebral palsy. The cost of caring for a disabled child is higher than what mothers interviewed in this study could afford. The costs incurred, included buying disposable nappies, milk as well as wheelchairs. Instead of concentrating on household chores and bringing food on the table, these mothers diverted their responsibility and concentrated more on the child with disability. Buying pampers and milk, feeding, and watching over the congenitally abnormal child becomes part of the mother's life. The findings of this current study are similar to what was found by Cousino and Hazen (2013) when they explored the factors in the child care that contributed most to the added strain. Their findings revealed that the demands for caring are created greater stress than the severity of the disability.

Moreover, these mothers were expected to take care of the other siblings who are not disabled. With the presence of a child with cerebral palsy, some mothers have to renounce some of these activities and devote most of their time to caring for the disabled child. They had no leisure time, as most of the time they had a duty to take care. Some of the mothers have to carry along this child wherever they go and some of the children were difficult to carry.

Some of the mothers interviewed in this study have to close their small businesses in order to attend to the child with congenital abnormalities. These small businesses were closed due to either the mother has to take the child for follow-ups in Windhoek or there was no one to look after the child at home or the child would spoil the business (child with a mental disorder). Some of the mothers who were earning an income through the formal employment thought of resigning from their work to attend to their children, though there were family members taking care of the child.

\subsection{Social Support}

All mothers interviewed in this study have acknowledged the role that the support system outside their families had played towards acceptance of their child's condition. Researchers who investigated the lived experiences of parents of children with disabilities has revealed the role of social support in improving the livelihood of parents of children with disability by strengthening their coping abilities. Bumin, Gunal, and Tukel (2008), has revealed that the ability of many families to adjust and cope with disabilities is determined by the availability and quality of support they receive.

Some mothers in this study accepted the condition of their child because of their belief in divine intervention. Their belief and trust in the Lord assisted them to cope positively with the condition of their child. They believed that God is the creator of this child with cerebral palsy, whatever happens to the child is left in the hands of the Lord. This faith they had in Jesus was the driving force behind their determination and perseverance to continue with the caring responsibilities.

While some of the mothers accepted the condition of their child because of their own faith in God, church pastors played a critical role in building self-belief to their members by calling upon divine help of the almighty, members would take it by faith and believe in their God. Some mothers confessed that church pastors had convinced them through the word of God to accept what God has given them. Mothers interviewed in this study confirm the 
findings of Burton et al. (2009) and related how social support systems such as religion, peers and formal services available in their community have assisted them to accept their children.

Meeting other mothers of children with similar conditions assisted some of the mothers interviewed in this study to cope with their child's condition. Some mothers interviewed in this study admitted that meeting other mothers of children born with congenital abnormalities at the hospital, assisted them to cope and accept their own children. During follow-up visits at the hospital, some mothers had an opportunity to compare their child's condition with other children and deduced that their child's condition was better than that of other disabled children. This has, however assisted mothers to cope positively with their child and eventually reduced the stress levels. Social support is important for health and stress relief; it increases resilience, multiplies joy, and softens sorrow (Scott, 2007). An important resource for coping with stress is social support; the presence of others in whom one can confide and from whom one can expect help and concern.

To conclude this theme, it is very clear from the perception raised by mothers of children born with disabilities that there is no system or framework in place to assist them to support them to alleviate the overwhelming stress, they are living with.

\subsection{Formal Services}

Mothers interviewed in this study had mixed perception regarding the quality of information and service they received from health care services. However, while some of the mothers have appreciated the service received from a health care professional, the majority of mothers were furious about the failure of health workers to disclose information about the disability of their child and so was the service.

Some mothers interviewed in this study were not informed about the congenital disorder of their child immediately after birth. They discovered the disability themselves at a later stage, this created a feeling of shame and disappointment to mothers as they expected health care professionals to inform them about the congenital abnormality of their child. In concurrence with Sajjad (2010), most parents in his study who visited professionals for help in the diagnosis or treatment of children suspected of being intellectually disabled, have reported frustrations and disappointments. No counselling was done to these mothers at least to assist them to grasp the reality of the gift they received. Meanwhile, failure to inform the mothers about the conditions of their child by health care professional has resulted in some mothers making improper decisions about their child. According to Bumin, Gunal, and Tukkel (2006), practitioners must be willing to discuss openly with families what is known about their child's handicap. Parents need this information in order to make sense of what is happening to their child and to enhance their ability to cope with this situation

\section{Conclusion}

The findings of this study lead to the conclusion that raising a child with CP is a source of stress, pain, anger and disappointment. Mothers suffer an emotional and physical trauma through rejection and stigmatization by family members/spouses. They have to go through a lot of challenges and they have to adjust their lifestyle to fit the situation which has resulted in increased levels of stress. The following adjustments were reported; a transition from an independent working mother to a full time caregiver, rescheduling of activities and relocation of workplaces to suit the child with cerebral palsy. Furthermore, there is no support system or framework in place to support mothers to alleviate the overwhelming stress. There are no counselling centers where they can overcome their psychological problems.

\section{Recommendation}

The following recommendations are made based on the study findings:

$\checkmark$ Coordinating body is highly recommended to give directions to parents of children with disability immediately after the final diagnosis is made.

$\checkmark$ It is recommended that, health providers and Faith Based Organization (FBO) must recognize and give support to the family members.

$\checkmark$ Nursing interventions designed to meet mothers' needs are important to reduce stress in parents of children with cerebral palsy. Interventions such as providing emotional support in the form of counseling, listening to parents' views, dissemination of proper and accurate information about the current situation and expectations for mothers of children with cerebral palsy may yield the best results thereby reducing stress levels.

$\checkmark$ An educational support program in the form of stress coping framework to be developed to support mothers of children with cerebral palsy. 


\section{Limitations of the Study}

In this study, it is at the reader's discretion to see how the results can be applied in other similar settings and circumstances.

\section{Acknowledgements}

The authors wish to thank all staffs from Oshana health directorate and mothers who willingly participated in this study. No funding was received for the study. There is no conflict of interest in this study

\section{References}

Bouman, N. H. (2008). The psychosocial adjustment of children with majorcongenital abdominal anomalies. PhD thesis. Sophia Children's Hospital Erasmus University, Department of Child and Adolescent Psychiatry

Braeneuner, S., \& Media, D. (2014). What Causes Increased Stress for Parents of Children With Special Needs: Nashville.

Bumin, G., Gunal, A., \& Tukel, D. (2008). Anxiety, depression and quality of life in mothers of disabled children. Journal o Pediatrics, 75(9), 901-906. https://doi.org/10.1007/s12098-008-0160-0

Burton, L., Westen, D., \& Kowalski, R. (2009). Psychology $2^{\text {nd }}$ Australian \& New Zealand Edition. Australia: John Wiley \& Sons.

Carsle, C., Mason, T., Watkins, E., \& Whitehead, E. (2005). The Stigma of Social Exclusion in Health Care. London and New York: Routiledge.Canada.

Contact a family. (2013). Relationship and caring for Disabled Child. UK: London. Retrieved from http://www.Cafamily.org.uk

Cousino, M. K., \& Hazen, R. A. (2013). Parenting Stress among Caregivers of Children with Chronic Illness: A Systematic Review. Journal of Pediatric, 38(8), 809. https://doi.org/10.1093/jpepsy/jst049

Karande, P., \& Kulkarni. (2008). Impact of an educational program on parental knowledge of cerebral palsy. Indian Journal of Pediatrics, 75(9), 901-906. https://doi.org/10.1007/s12098-008-0160-0

Ministry of Lands, Resettlement and Rehabilitation. (1997). National Policy on Disability. Republic of Namibia. Windhoek.

Namibia. (2001). National Population and Housing Survey. Namibia: Windhoek.

Rozenweig, J. M., \& Huffstutter, K. (2003). Integrating employment with parenting of children having mental challenges. Paper presented at annual meeting of the Western Psychology Association, Vancouver: Canada.

Sajjad, S. (2010). Stress Faced by Mothers of Children with Intellectual Disability and its Impact on their Family Life. University of Karachi: Pakistan.

Scharer, K., Colon, E., Moneyham, L., Tavakoli, A., \& Shugart M. (2009). A comparison of two types of social support for mothers of children of Mentally Ill Children. Journal of Child and Adolescent Psychiatric Nursing, 22(2), 86-98. https://doi.org/10.1111/j.1744-6171.2009.00177.x

Scott, E. (2007). Mother Friends: How Mothers Can Use Friends to Relieve Stress. Retrieved from About.com Guide.

\section{Copyrights}

Copyright for this article is retained by the author(s), with first publication rights granted to the journal.

This is an open-access article distributed under the terms and conditions of the Creative Commons Attribution license (http://creativecommons.org/licenses/by/4.0/). 